\title{
Germplasm evaluation of heat tolerance in bread wheat in Tel Hadya, Syria
}

\author{
Emeka C. Okechukwu ${ }^{1 *}$, Christain U. Agbo ${ }^{1}$, Michael I. Uguru ${ }^{1}$, \\ and Francis C. Ogbonnaya ${ }^{2}$
}

\section{ABSTRACT}

Breeding for heat tolerance in bread wheat (Triticum aestivum L.) is a serious global concern due to the increasing threats of high temperature. Thus, 189 wheat genotypes coded from 1 to 189 were evaluated for heat tolerance in normal and late seasons in the International Centre for Agricultural Research in Dry Areas (ICARDA), Tel Hadya, Syria, from 2010 to 2012. The experiments were laid out in alpha lattice designs with two replicates. Data collected on the grain yield, days to heading and maturity, grain filling duration and plant height were subjected to restricted maximum likelihood (REML) analysis for generation of the best linear unbiased estimates (BLUEs). Very highly significant effects $(\mathrm{p} \leq 0.001)$ of genotype, season, and genotype by season interaction on grain yield and other traits were obtained. The grain yield and other traits performance of the wheat genotypes were significantly $(\mathrm{p} \leq 0.05)$ higher in the normal season than in the late season. Genotype 148 was among the 30 top grain yielding genotypes in all the environments, while genotypes 172 and 124 were among the top yielding genotypes in all the environments except in late season 2 . The relative heat tolerance of the genotypes ranged from $-33.69 \%$ to $-77.95 \%$ in late season $1 \mathrm{vs}$. normal season 1 and $-65.28 \%$ to $-95.83 \%$ in late season $2 \mathrm{vs}$. normal season 2 . The high variability obtained in the germplasm underlies sufficient genetic variability for improving heat tolerance in bread wheat.

Key words: Bread wheat germplasm, evaluation, grain yield, heat tolerance, Triticum aestivum.

${ }^{1}$ University of Nigeria, Department of Crop Science, 410001, Nsukka, Nigeria. "Corresponding author (emeka.okechukwu@unn.edu.ng).

${ }^{2}$ Grains Research and Development Corporation (GRDC), P.O. Box 5367, Kingston, Australia.

Received: 12 May 2015.

Accepted: 3 October 2015.

doi:10.4067/S0718-58392016000100002

\section{INTRODUCTION}

Wheat (Triticum aestivum L.) is one of the most important staple food crops of the world, occupying $17 \%$ of crop acreage worldwide, feeding about $40 \%$ of the world population and providing $20 \%$ of total food calories and protein in human nutrition (Gupta et al., 2008). As a major staple food in many parts of the world, it will continue to attract considerable research attentions in the face of the challenge of feeding projected population of 9 billion by 2050. Yield increases are essential to meet this demand, as expanding the wheat area is not feasible (Rajaram and Braun, 2008). Gill et al. (2004) stated that in order to meet growing human needs; wheat grain production must increase at an annual rate of $2 \%$. Unfortunately, heat stress is a major environmental factor that substantially reduces wheat grain yield globally especially in arid, semi-arid, tropical, and sub-tropical regions that are associated with higher temperature. Wahid et al. (2007) defined heat stress as the rise in temperature beyond a threshold level for a period of time sufficient to cause irreversible damage to plant growth and development. Heat stress can cause partial or total breakdown of anatomy, morphology, biochemistry and physiology of the crop. It is a function of the magnitude and rate of temperature increase, as well as the duration of exposure to the raised temperature (Wahid et al., 2007).

End-of-season or 'terminal' heat stress is also likely to increase for wheat in the near future (Semenov, 2009) due to increase in global warming. Therefore, breeding for heat tolerance in wheat is a major global concern (Paliwal et al., 2012). Consequently, development of heat-tolerant cultivars is of importance in wheat breeding programs (Sikder and Paul, 2010; Mohamed, 2013). Success in crop improvement generally depends on the magnitude of genetic variability and the extent to which the desirable characters are heritable (Kahrizi et al., 2010). The knowledge from the germplasm evaluation will be of great significance for selection of heat tolerant genotypes and also for improving grain yield under high temperature. Thus, the objectives of the research were to study the genetic variability of 189 elite ICARDA wheat genotypes under high temperature, and to identify the heat tolerant genotypes for heat stressed environments. 


\section{MATERIALS AND METHODS}

\section{Genetic materials and experimental sites}

One hundred and eighty-nine elite wheat germplasms of International Centre for Agricultural Research in Dry Areas (ICARDA), Tel Hadya, Syria, were evaluated for heat tolerance in normal season (heat favorable condition) and late season (heat stressed season) in Tel Hadya $\left(36^{\circ} 6^{\prime} \mathrm{N}\right.$, $36^{\circ} 56^{\prime}$ E; 284 m a.s.1.), Aleppo, Syria, from 2010 to 2012. Each season trial was done for $2 \mathrm{yr}$. The first year for the normal season was from December 2010 to July 2011 (Table 1), while the second year trial lasted from December 2011 to July 2012 (Table 2). The first year for the late season was from April 2011 to July 2011 (Table 3), whereas the second year began in April 2012 and ended in July 2012 (Table 4). Tel Hadya is located on Northern Syria with long-term average annual rainfall of $350 \mathrm{~mm}$. The soil at Tel Hadya is fine clay, thermic, chromic Calcixererts, merging into a calcixerollic xerochrept in some areas (Ryan et al., 1997).

\section{Heat tolerance evaluation of the germplasm}

The experiments were laid out in an alpha lattice design with two replicates. Each plot consisted of six to eight rows, $8 \mathrm{~m}$ long with a cut back to $6 \mathrm{~m}, 0.15 \mathrm{~m}$ spacing between rows, and $0.9 \mathrm{~m}$ wide plots. Data were collected on days to heading (d), days to maturity (d), grain filling duration (d), plant height $(\mathrm{cm})$, and grain yield $\left(\mathrm{t} \mathrm{ha}^{-1}\right)$. Days to heading $(\mathrm{DH})$, which is duration between dates of sowing and displaying of heads, was taken at the stage when more than $50 \%$ plants in each plot exhibited heads (Zadoks stage 59, Zadoks et al., 1974). Days to maturity was taken at the period between date of sowing and date when more than 50\% spikes in a plot showed a total loss of green color (physiological maturity) (Zadoks stage 89, Zadoks et al., 1974). Grain filling duration was calculated as the difference between days to heading and days to maturity. Plant height of each genotype was estimated when all plots reached physiological maturity by measuring the distance between the base of the stem and the top of the spike excluding the awn. The measurement was done with metric ruler. Grain yield was measured by weighing wheat seeds from $1 \mathrm{~m}^{2}$ for each plot, and later converted into tha- ${ }^{-1}$.

\section{Statistical analyses}

Restricted maximum likelihood (REML) analysis for generation of the best linear unbiased estimates (BLUEs) and regressional variance components were performed on data collected using GenStat Release 10.3DE (VSN International, Hemel Hempstead, UK). Genotypes were treated as fixed effect, while blocks within replicates were treated as random effect. The relative heat tolerance was calculated by the formula $(Y h-Y c) / Y c) \times 100 \%$ as described by Haque et al. (2009), where $Y h$ is grain yield in the heat stressed condition (late season), $Y c$ is grain yield in the control (normal season).

Table 1. Meteorological information of the normal season 1 (favorable condition) in Tel Hadya, Syria, during the growing period of the wheat germplasm.

\begin{tabular}{|c|c|c|c|c|c|c|c|}
\hline Month & Max. Temp & Min. Temp & Av. Temp & Max. RH & Min. RH & Av. RH & Ppt \\
\hline & 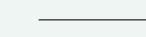 & $-{ }^{\circ} \mathrm{C}-$ & 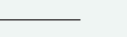 & 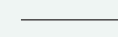 & $-\%$ & - & $\mathrm{mm}$ \\
\hline $\operatorname{Dec}(2010)$ & 12.97 & 3.47 & 8.22 & 92.55 & 60.78 & 76.66 & 69.60 \\
\hline Jan (2011) & 13.00 & 2.50 & 7.75 & 93.84 & 54.79 & 74.31 & 40.80 \\
\hline Feb (2011) & 14.93 & 3.06 & 8.99 & 95.81 & 49.85 & 72.83 & 42.10 \\
\hline Mar (2011) & 19.34 & 4.03 & 11.68 & 96.66 & 39.36 & 68.01 & 24.40 \\
\hline April (2011) & 23.46 & 7.76 & 15.61 & 95.42 & 36.46 & 65.94 & 44.60 \\
\hline May (2011) & 28.64 & 12.17 & 20.40 & 90.92 & 30.40 & 60.66 & 10.10 \\
\hline June (2011) & 34.55 & 18.51 & 26.53 & 78.41 & 20.81 & 52.61 & 0.50 \\
\hline July (2011) & 34.00 & 20.20 & 27.10 & 79.70 & 26.50 & 53.10 & 0.00 \\
\hline Mean & 22.61 & 8.96 & 15.79 & 90.41 & 39.87 & 65.51 & 29.01 \\
\hline
\end{tabular}

Max. Temp: Maximum temperature, Min. Temp: minimum temperature, Av. Temp: average temperature, Max. RH: maximum relative humidity, Min. RH: minimum relative humidity, Av. RH: average relative humidity, Ppt: precipitation.

Table 2. Meteorological information of the normal season 2 (favorable condition) in Tel Hadya, Syria, during the growing period of the wheat germplasm.

\begin{tabular}{|c|c|c|c|c|c|c|c|}
\hline Month & Max. Temp & Min. Temp & Av. Temp & Max. RH & Min. $\mathrm{RH}$ & Av. RH & Ppt \\
\hline & $\longrightarrow$ & $-{ }^{\circ} \mathrm{C}$ & - & 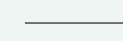 & $-\%$ & - & $\mathrm{mm}$ \\
\hline Dec (2011) & 12.57 & 1.42 & 6.99 & 97.68 & 61.36 & 79.52 & 68.60 \\
\hline Jan (2012) & 10.55 & 2.65 & 6.60 & 98.61 & 70.10 & 84.36 & 120.30 \\
\hline Feb (2012) & 12.99 & 1.31 & 7.15 & 94.29 & 45.51 & 69.90 & 104.80 \\
\hline Mar (2012) & 16.11 & 2.82 & 9.47 & 93.39 & 36.94 & 65.16 & 33.50 \\
\hline April (2012) & 26.59 & 8.65 & 17.62 & 92.47 & 28.56 & 60.51 & 3.20 \\
\hline May (2012) & 29.33 & 13.39 & 21.36 & 88.71 & 31.74 & 60.22 & 4.60 \\
\hline June (2012) & 37.41 & 19.20 & 28.30 & 75.05 & 20.64 & 47.84 & 2.50 \\
\hline July (2012) & 37.86 & 21.80 & 29.83 & 62.14 & 20.05 & 41.09 & 0.00 \\
\hline Mean & 22.93 & 8.90 & 15.91 & 87.79 & 39.36 & 63.58 & 42.19 \\
\hline
\end{tabular}

Max. Temp: Maximum temperature, Min. Temp: minimum temperature, Av. Temp: average temperature, Max. R/H: maximum relative humidity, Min. R/H: minimum relative humidity, Av. R/H: average relative humidity, Ppt: precipitation. 
Table 3. Meteorological information of the late season 1 (heat stressed season) in Tel Hadya, Syria, during the growing period of the wheat germplasm.

\begin{tabular}{|c|c|c|c|c|c|c|c|}
\hline Month & Max. Temp & Min. Temp & Av. Temp & Max. RH & Min. RH & Av. RH & Ppt \\
\hline & & $-{ }^{\circ} \mathrm{C}$ & 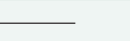 & & $-\%$ & - & $\mathrm{mm}$ \\
\hline April (2011) & 23.27 & 7.63 & 15.45 & 96.01 & 37.33 & 66.67 & 44.50 \\
\hline May(2011) & 28.64 & 12.17 & 20.40 & 90.92 & 30.40 & 60.66 & 10.10 \\
\hline June(2011) & 34.55 & 18.51 & 26.53 & 78.41 & 26.81 & 52.61 & 0.50 \\
\hline July(2011) & 38.76 & 22.09 & 30.42 & 69.92 & 23.58 & 46.75 & 0.00 \\
\hline Mean & 31.30 & 15.10 & 23.20 & 83.81 & 29.53 & 56.67 & 13.78 \\
\hline
\end{tabular}

Max. Temp: Maximum temperature, Min. Temp: minimum temperature, Av. Temp: average temperature, Max. R/H: maximum relative humidity, Min. R/H: minimum relative humidity, Av. R/H: average relative humidity, Ppt: precipitation.

Table 4. Meteorological information of the late season 2 (heat stressed season) in Tel Hadya, Syria, during the growing period of the wheat germplasm.

\begin{tabular}{|c|c|c|c|c|c|c|c|}
\hline Month & Max. Temp & Min. Temp & Av. Temp & Max. RH & Min. RH & Av. RH & Ppt \\
\hline & 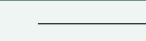 & $-{ }^{\circ} \mathrm{C}$ & - & 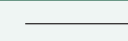 & $-\%$ & - & $\mathrm{mm}$ \\
\hline April (2012) & 30.94 & 10.83 & 20.88 & 85.30 & 20.68 & 52.99 & 0.00 \\
\hline May (2012) & 29.33 & 13.39 & 21.36 & 88.71 & 31.74 & 60.22 & 4.60 \\
\hline June (2012) & 37.41 & 19.20 & 28.30 & 75.05 & 20.64 & 47.84 & 2.50 \\
\hline July (2012) & 39.64 & 22.80 & 31.22 & 66.22 & 21.61 & 43.92 & 0.00 \\
\hline Mean & 34.33 & 16.55 & 25.44 & 78.82 & 23.67 & 51.24 & 1.78 \\
\hline
\end{tabular}

Max. Temp: Maximum temperature, Min. Temp: minimum temperature, Av. Temp: average temperature, Max. RH: maximum relative humidity, Min. RH: minimum relative humidity, Av. RH: average relative humidity, Ppt: precipitation.

Pearson's correlation coefficients of the traits were obtained using SPSS version 16 software (SPSS, Chicago, Illinois, USA). Broad sense heritability $\left(h^{2}\right)$ was calculated from the accumulated unbalanced ANOVA as explained by Fehr $\left.(1993) ; h^{2}=G V / P V\right) \times 100 \% ; E V=M S r ; G V=(M S g-$ $M S r) / R ; P V=E V+G V$. Where $\mathrm{GV}$ is genotypic variance, $\mathrm{PV}$ is phenotypic variance, $\mathrm{EV}$ is environmental variance, $\mathrm{MSr}$ is mean square error, MSg is mean square genotype, and $\mathrm{R}$ is number of replicates. Genetic advance (GA) was calculated according to Johnson et al. (1955) as follows; GA $=\mathrm{K}(\mathrm{GV} / \sqrt{\mathrm{PV}})$; where $\mathrm{K}$ is 2.06 at $5 \%$ selection intensity.

\section{RESULTS}

\section{Effects of genotype, season and genotype by season interaction on the germplasm}

Tables 5 and 6 revealed that the effects (mean squares) of genotype (G), season (S), and Genotype by Season $(\mathrm{G} \times \mathrm{S})$ interaction on grain yield and days to heading were consistently very highly significant $(\mathrm{p} \leq 0.001)$. The effect of $\mathrm{S}$ was consistently much greater than its corresponding effects due to $\mathrm{G}$, and $\mathrm{G} \times \mathrm{S}$ on each of the traits. Moreover, the effect of $\mathrm{G}$ was constantly greater than its corresponding effect of $\mathrm{G} \times \mathrm{S}$ except in days to maturity $(\mathrm{G}=21.84$ and $\mathrm{G} \times \mathrm{S}=22.76)$ and grain yield $(\mathrm{G}=0.27$ and $\mathrm{G} \times \mathrm{S}=0.32)$ in Table 6.

\section{Grain yield and other traits performance of the wheat genotypes in the seasons}

The wheat germplasm performance in all the traits measured was significantly $(\mathrm{p} \leq 0.05)$ higher in the normal season than in the late season (Table 7). Table 8 showed the thirty top grain yielding genotypes in each of the four environments (late season 1, late season 2, normal season 1, and normal season 2) with mean grain yield of $1.91,1.23,3.80$, and 5.42 $\mathrm{t} \mathrm{ha}^{-1}$ in the four environments, respectively. In late season 1 , grain yield ranged from 1.74 in genotype 16 to $2.32 \mathrm{t} \mathrm{ha}^{-1}$ in genotype 148, while in late season 2 it extended from 1.15 in genotypes 18,73 , and 91 to $1.37 \mathrm{t} \mathrm{ha}^{-1}$ in genotype 72 . It ranged from 3.63 in genotype 64 to $4.09 \mathrm{t} \mathrm{ha}^{-1}$ in genotype 146 in the normal season 1 , whereas it stretched from 5.15 in genotype 143 to $5.94 \mathrm{t} \mathrm{ha}^{-1}$ in genotype 81 in the normal season 2. However, there was nonsignificant difference among these genotypes in each of the environments. Consistently, genotype 148 was among the 30 top yielding

Table 5. Analysis of variance of agronomic traits of 189 wheat genotypes as influenced by late season 1 and normal season 1.

\begin{tabular}{|c|c|c|c|c|c|c|c|c|}
\hline Traits & $\mathrm{NG}$ & REP & $\mathrm{NE}$ & MSG & MSS & $\mathrm{MS}(\mathrm{G} \times \mathrm{S})$ & MSR & $\mathrm{CV}(\%)$ \\
\hline $\mathrm{DH}, \mathrm{d}$ & 189 & 2 & 2 & $13.61^{* * *}$ & $655913.48^{* * *}$ & $11.63^{* * *}$ & 0.87 & 1.29 \\
\hline DM, d & 189 & 2 & 1 & $7.23^{* * *}$ & - & - & 1.09 & 1.55 \\
\hline GFD, d & 189 & 2 & 1 & $6.19^{* * * *}$ & - & - & 1.85 & 5.56 \\
\hline $\mathrm{PH}, \mathrm{cm}$ & 189 & 2 & 2 & $57.89^{* * *}$ & $144264.21^{* * *}$ & $27.20^{* * *}$ & 16.74 & 7.26 \\
\hline $\mathrm{GY}, \mathrm{t}$ ha ${ }^{-1}$ & 189 & 2 & 2 & $0.20^{* * *}$ & $674.54^{* * *}$ & $0.11^{* *}$ & 0.08 & 11.87 \\
\hline
\end{tabular}

DH: Days to heading, DM: days to maturity, GFD: grain filling duration, PH: plant height, GY: grain yield, NG: number of genotypes, REP: number of replicates, NE: number of environments, MSG: mean square for genotype, MSS: mean square for season, MS(G×S): mean square for genotype by season interaction, MSR: mean square for error, CV: coefficient of variation. 
Table 6. Analysis of variance of agronomic traits of 189 wheat genotypes as influenced by late season 2 and normal season 2.

\begin{tabular}{|c|c|c|c|c|c|c|c|c|}
\hline Traits & $\mathrm{NG}$ & REP & $\mathrm{NE}$ & MSG & MSS & $\mathrm{MS}(\mathrm{G} \times \mathrm{S})$ & MSR & $\mathrm{CV}(\%)$ \\
\hline $\mathrm{DH}, \mathrm{d}$ & 189 & 2 & 2 & $10.49^{* * * *}$ & $840933.59^{* * *}$ & $7.95^{* * * *}$ & 0.54 & 0.92 \\
\hline DM, d & 189 & 2 & 2 & $21.84^{* * *}$ & $1069810.48^{* * *}$ & $22.76^{* * *}$ & 3.11 & 1.62 \\
\hline GFD, $d$ & 189 & 2 & 2 & $12.24^{* * *}$ & $13757.44^{* * *}$ & $8.57^{* * *}$ & 2.75 & 5.69 \\
\hline $\mathrm{PH}, \mathrm{cm}$ & 189 & 2 & 1 & $44.17^{* * *}$ & - & - & 7.74 & 5.32 \\
\hline $\mathrm{GY}, \mathrm{t} \mathrm{ha}^{-1}$ & 189 & 2 & 2 & $0.27^{* * *}$ & $2840.30^{* * *}$ & $0.32^{* * * *}$ & 0.17 & 14.86 \\
\hline
\end{tabular}

DH: Days to heading, DM: days to maturity, GFD: grain filling duration, PH: plant height, GY: grain yield, NG: number of genotypes, REP: number of replicates, NE: number of environments, MSG: mean square for genotype, MSS: mean square for season, MS(G×S): mean square for genotype by season interaction, MSR: mean square for error, CV: coefficient of variation.

Table 7. Combined analysis of the effect of season on the agronomic performance of bread wheat germplasm.

\begin{tabular}{lccccc}
\hline Seasons & $\begin{array}{c}\text { Days to } \\
\text { heading }\end{array}$ & $\begin{array}{c}\text { Days to } \\
\text { maturity }\end{array}$ & $\begin{array}{c}\text { Grain filling } \\
\text { duration }\end{array}$ & $\begin{array}{c}\text { Plant } \\
\text { height }\end{array}$ & $\begin{array}{c}\text { Grain } \\
\text { yield }\end{array}$ \\
\cline { 2 - 4 } Normal & 107.7 & 146.8 & 33.41 & 70.49 & 4.035 \\
Late & 44.86 & 69.5 & 24.67 & 47.42 & 1.101 \\
Mean & 76.28 & 108.15 & 29.04 & 58.955 & 2.568 \\
F-LSD (0.05) & 6.914 & 2.646 & 0.8722 & 6.24 & 0.9108 \\
\hline
\end{tabular}

genotypes in each of the environments, while genotypes 172 and 124 were among the top yielding genotypes in all the environments except in late season 2. Genotypes 22, 30, 60, 69,58 , and 148 were consistently among the top yielding genotypes in the two late seasons only, while genotypes 38 , $49,51,124,148,162$, and 172 were consistent only in the two normal seasons.

\section{Relative heat tolerance (RHT) of wheat germplasm}

Figures 1 and 2 showed the grain yield plasticity/stability of the genotypes in the late seasons (heat stressed environments) respect to their corresponding normal seasons (control/ heat favorable environments). In Figure 1 (late season 1 vs. normal season 1), the RHT ranged from $-33.69 \%$ in genotype 168 to $-77.95 \%$ in genotype 167, while in Figure 2 (late season 2 vs. normal season 2), it ranged from $-65.28 \%$ in genotype 47 to $-95.83 \%$ in genotype 99 . Consistently, only genotypes 119 and 30 were among the 15 most heat tolerant genotypes in the two figures. As earlier reported, genotype 30 was also among the 30 top yielding genotypes in the two late seasons. Genotype 148 that was among the 30 top grain yielding genotypes in the four environments was among the

Table 8. Best linear unbiased estimates (BLUE) of grain yield $\left(\mathrm{tha}^{-1}\right)$ of the 30 top yielding genotypes in each of the environment.

\begin{tabular}{|c|c|c|c|c|c|c|c|}
\hline GEN(L1) & GY(L1) & GEN(L2) & GY(L2) & GEN(N1) & GY(N1) & GEN(N2) & GY(N2) \\
\hline 148 & 2.32 & 72 & 1.37 & 146 & 4.09 & 81 & 5.94 \\
\hline 172 & 2.22 & 24 & 1.37 & 162 & 4.08 & 109 & 5.86 \\
\hline 156 & 2.12 & 77 & 1.34 & 148 & 4.05 & 134 & 5.71 \\
\hline 179 & 2.11 & 30 & 1.33 & 18 & 3.98 & 37 & 5.69 \\
\hline 140 & 2.07 & 81 & 1.33 & 160 & 3.98 & 38 & 5.57 \\
\hline 90 & 2.02 & 60 & 1.31 & 115 & 3.96 & 114 & 5.55 \\
\hline 119 & 2.01 & 35 & 1.30 & 157 & 3.94 & 106 & 5.54 \\
\hline 113 & 1.98 & 26 & 1.25 & 17 & 3.89 & 162 & 5.53 \\
\hline 166 & 1.98 & 83 & 1.23 & 116 & 3.87 & 83 & 5.52 \\
\hline 124 & 1.97 & 22 & 1.23 & 124 & 3.83 & 49 & 5.50 \\
\hline 21 & 1.94 & 58 & 1.23 & 48 & 3.80 & 88 & 5.46 \\
\hline 168 & 1.91 & 7 & 1.22 & 186 & 3.80 & 99 & 5.46 \\
\hline 30 & 1.90 & 54 & 1.22 & 50 & 3.78 & 172 & 5.45 \\
\hline 159 & 1.89 & 135 & 1.22 & 104 & 3.78 & 43 & 5.44 \\
\hline 76 & 1.88 & 148 & 1.22 & 140 & 3.77 & 20 & 5.43 \\
\hline 87 & 1.85 & 69 & 1.21 & 51 & 3.76 & 142 & 5.41 \\
\hline 115 & 1.85 & 120 & 1.19 & 28 & 3.75 & 135 & 5.37 \\
\hline 102 & 1.83 & 17 & 1.19 & 159 & 3.73 & 21 & 5.37 \\
\hline 60 & 1.82 & 27 & 1.19 & 155 & 3.73 & 152 & 5.35 \\
\hline 178 & 1.81 & 71 & 1.18 & 131 & 3.71 & 148 & 5.32 \\
\hline 182 & 1.81 & 142 & 1.18 & 156 & 3.71 & 123 & 5.31 \\
\hline 107 & 1.80 & 80 & 1.18 & 141 & 3.71 & 125 & 5.25 \\
\hline 117 & 1.80 & 137 & 1.18 & 145 & 3.70 & 128 & 5.24 \\
\hline 97 & 1.79 & 59 & 1.17 & 172 & 3.68 & 124 & 5.24 \\
\hline 69 & 1.77 & 36 & 1.16 & 49 & 3.67 & 51 & 5.23 \\
\hline 22 & 1.75 & 33 & 1.16 & 138 & 3.67 & 44 & 5.21 \\
\hline 79 & 1.75 & 150 & 1.16 & 58 & 3.65 & 89 & 5.18 \\
\hline 58 & 1.75 & 18 & 1.15 & 66 & 3.65 & 189 & 5.18 \\
\hline 170 & 1.75 & 91 & 1.15 & 38 & 3.64 & 19 & 5.16 \\
\hline 16 & 1.74 & 73 & 1.15 & 64 & 3.63 & 143 & 5.15 \\
\hline MEAN & 1.91 & & 1.23 & & 3.80 & & 5.42 \\
\hline F-LSD $(0.05)$ & 0.63 & F-LSD & 0.31 & F-LSD & 0.59 & F-LSD & 0.99 \\
\hline
\end{tabular}

GEN: Genotype, L1: late season 1, L2: late season 2, N1: normal season 1, N2: normal season 2, GY grain yield (t ha-1). 
Figure 1. Percentage change in grain yield (\%) of the wheat germplasm in late season 1 respect to the control (normal season 1$)$ in Tel Hadya, Syria.

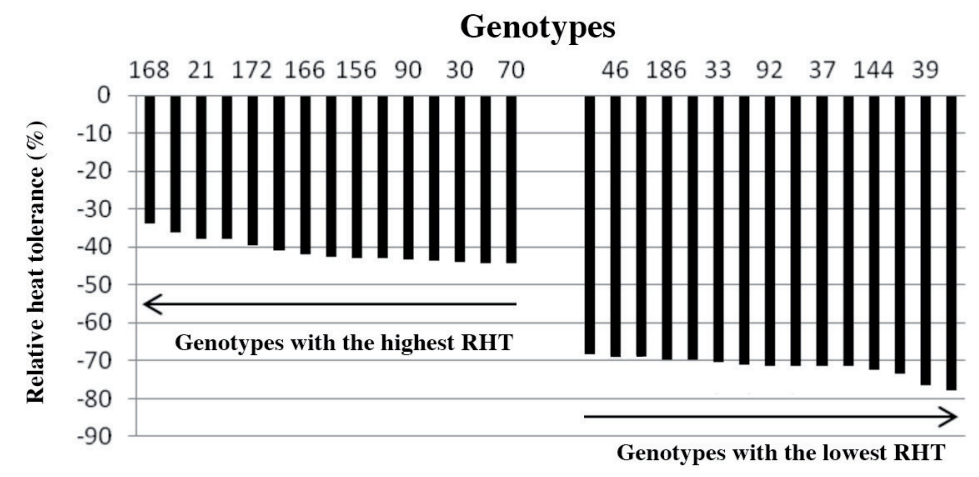

RHT: Relative heat tolerance.

Figure 2. Percentage change in grain yield (\%) of the wheat germplasm in late season 2 respect to the control (normal season 2 ) in Tel Hadya, Syria.

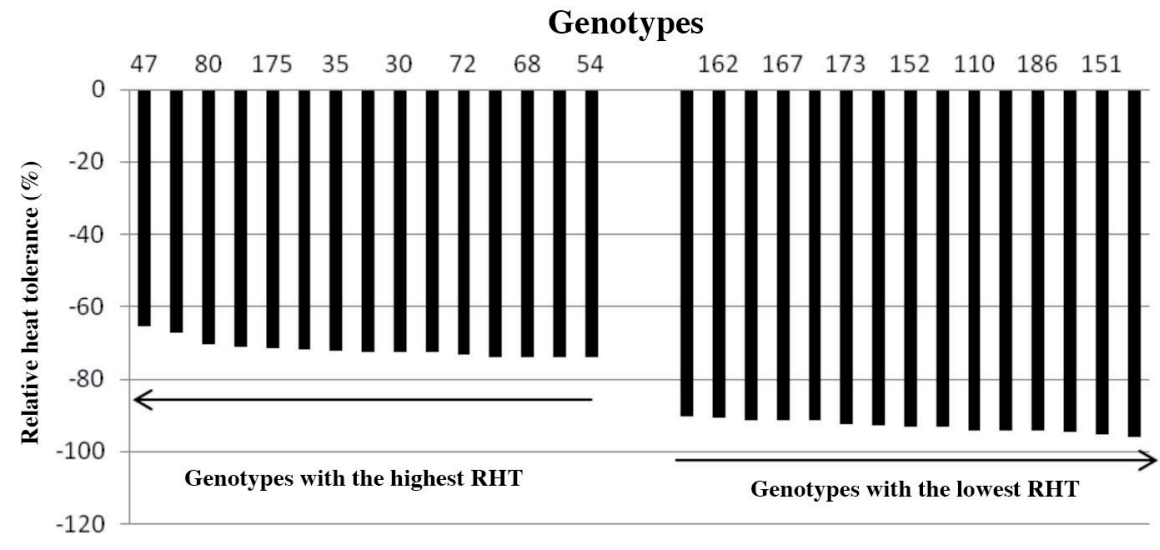

RHT: Relative heat tolerance.

15 most heat tolerant genotypes in the Figure 1 only (late season $1 v s$. normal season 1 ).

\section{Association of the grain yield with other traits in the seasons}

Days to heading (DH) negatively correlated with grain yield (GY) in the two late seasons, though only significant in the late season $2\left(\mathrm{P} \leq 0.01, \mathrm{r}=-0.58^{* *}\right)$ (Table 9). In the normal season 1 , there was nonsignificant positive correlation between DH and GY, but no correlation appeared to exist between the traits in normal season 2 . Days to maturity (DM) had significant negative correlation with GY (P $\left.\leq 0.01, \mathrm{r}=-0.59^{* *}\right)$ in the late season 2 , but had nonsignificant positive correlation in the late season $1(\mathrm{r}=0.01)$. DM had positive significant correlation with GY in normal season $2\left(\mathrm{p} \leq 0.01, \mathrm{r}=0.17^{* *}\right)$. Grain filling duration (GFD) correlated positively with $G Y$ in late season $1\left(\mathrm{r}=0.13^{*}\right)$, but negatively correlated with GY in late season $2\left(r=-0.34^{* *}\right)$. In addition, GFD had positive significant correlation with $\mathrm{GY}$ in normal season $2(\mathrm{r}=$ $0.22 * *)$. Plant height had significant positive correlation with GY in the three environments where the trait was measured (late season $1=0.61 * *$, late season $2=0.34 * *$, and normal season $1=0.20 * *$ ).

\section{Broad sense heritability and genetic advance estimates of the traits in the seasons}

Broad sense heritability (range $=0.69$ to 0.94 with a mean of 0.85 ) was consistently high in days to heading and days to maturity (range $=0.69$ to 0.85 with a mean of 0.76 ) (Table 10). GFD had moderate heritability values that ranged from 0.53 in normal season 2 to 0.66 in late season 2, with a mean of 0.60 . PH had high heritability value $(0.70)$ in late season 2 , moderate value (0.59) in normal season 1 and low value of 0.29 in late season 1 with a mean value of 0.53 . GY was low in the heritability values in all the environments except in late season 2 that it showed moderately high value of 0.60 . However, the mean value for GY was still low (0.39). Mean genetic advance estimates for the traits were highest in PH (6.05), followed by $\mathrm{DM}$ (4.78), DH (4.15), GFD (3.04), and GY (0.28) in that order (Table 11). The genetic estimates of each trait varied across the environments, but GY showed very close genetic advance estimates across the environments, followed by GFD. 
Table 9. Pearson correlation of grain yield and other studied traits of wheat germplasm in each of the environments.

\begin{tabular}{|c|c|c|c|c|c|}
\hline \multicolumn{6}{|c|}{ Late 1} \\
\hline Traits & DH & DM & GFD & PH & GY \\
\hline DH & 1.00 & & & & \\
\hline DM & $0.73^{* *}$ & 1.00 & & & \\
\hline GFD & $-0.74^{* * *}$ & -0.08 & 1.00 & & \\
\hline PH & 0.09 & $0.19^{* *}$ & 0.06 & 1.00 & \\
\hline GY & -0.08 & 0.01 & $0.13^{*}$ & $0.61^{* *}$ & 1.00 \\
\hline \multicolumn{6}{|c|}{ Late 2} \\
\hline Traits & DH & DM & GFD & PH & GY \\
\hline DH & 1.00 & & & & \\
\hline DM & $0.73^{* *}$ & 1.00 & & & \\
\hline GFD & $0.17^{* *}$ & $0.79^{* *}$ & 1.00 & & \\
\hline PH & $-0.41^{* *}$ & $-0.33^{* * *}$ & $-0.11^{*}$ & 1.00 & \\
\hline GY & $-0.58^{* *}$ & $-0.59^{* * *}$ & $-0.34^{* *}$ & $0.34^{* *}$ & 1.00 \\
\hline \multicolumn{6}{|c|}{ Normal 1} \\
\hline Traits & DH & PH & GY & & \\
\hline DH & 1.00 & & & & \\
\hline PH & -0.08 & 1.00 & & & \\
\hline GY & 0.06 & $0.20^{* *}$ & 1.00 & & \\
\hline \multicolumn{6}{|c|}{ Normal 2} \\
\hline Traits & DH & DM & GFD & GY & \\
\hline DH & 1.00 & & & & \\
\hline DM & $0.64^{* *}$ & 1.00 & & & \\
\hline GFD & 0.04 & $0.79^{* * *}$ & 1.00 & & \\
\hline GY & 0.00 & $0.17^{* *}$ & $0.22^{* *}$ & 1.00 & \\
\hline
\end{tabular}

DH: Days to heading (d), DM: days to maturity (d), GFD: grain filling duration (d), PH: plant height $(\mathrm{cm}), \mathrm{GY}$ : grain yield $\left(\mathrm{t} \mathrm{ha}^{-1}\right)$, Late 1: late season 1, Late 2: late season 2, Normal 1: normal season 1, Normal 2: normal season 2 .

Table 10. Broad sense heritability estimates of all the agronomic traits studied in each of the environments.

\begin{tabular}{lccccc}
\hline & \multicolumn{5}{c}{ Environments } \\
\cline { 2 - 5 } Traits & $\begin{array}{c}\text { Late } \\
\text { Season 1 }\end{array}$ & $\begin{array}{c}\text { Late } \\
\text { Season 2 }\end{array}$ & $\begin{array}{c}\text { Normal } \\
\text { Season 1 }\end{array}$ & $\begin{array}{c}\text { Normal } \\
\text { Season 2 }\end{array}$ & Mean \\
\hline DH & 0.90 & 0.94 & 0.69 & 0.85 & 0.85 \\
DM & 0.75 & 0.85 & - & 0.69 & 0.76 \\
GFD & 0.61 & 0.66 & - & 0.53 & 0.60 \\
PH & 0.29 & 0.70 & 0.59 & - & 0.53 \\
GY & 0.32 & 0.60 & 0.40 & 0.24 & 0.39 \\
\hline
\end{tabular}

DH: Days to heading (d), DM: days to maturity (d), GFD: grain filling duration (d), PH: plant height (cm), GY: grain yield $\left(\mathrm{t} \mathrm{ha}^{-1}\right)$.

Table 11. Genetic advance estimates of all the agronomic traits studied in each of the environments.

\begin{tabular}{lccccc}
\hline & \multicolumn{5}{c}{ Environments } \\
Traits & $\begin{array}{c}\text { Late } \\
\text { Season 1 }\end{array}$ & $\begin{array}{c}\text { Late } \\
\text { Season 2 }\end{array}$ & $\begin{array}{c}\text { Normal } \\
\text { Season 1 }\end{array}$ & $\begin{array}{c}\text { Normal } \\
\text { Season 2 }\end{array}$ & Mean \\
\hline DH & 6.59 & 4.85 & 2.26 & 2.91 & 4.15 \\
DM & 3.62 & 7.07 & - & 3.64 & 4.78 \\
GFD & 2.99 & 3.83 & - & 2.30 & 3.04 \\
PH & 3.81 & 7.37 & 6.97 & - & 6.05 \\
GY & 0.27 & 0.33 & 0.26 & 0.27 & 0.28 \\
\hline
\end{tabular}

DH: Days to heading (d), DM: days to maturity (d), GFD: grain filling duration (d), PH: plant height (cm), GY: grain yield $\left(\mathrm{t} \mathrm{ha}^{-1}\right)$.

\section{DISCUSSION}

The significant effects of $\mathrm{G}, \mathrm{E}$, and $\mathrm{G} \times \mathrm{E}$ obtained agree with the results of Motamedi et al. (2012), Tadesse et al. (2012), Degewione et al. (2013), and Mohamed (2013). The much greater effect of season on all the traits when compared with effects of genotype and genotype by season interaction reveals that most of the observed variations in the wheat germplasm are mainly due to seasonal (environmental) effects. Furthermore, the significant genotype by season interaction observed showed that each genotype responded differently to the two seasons in respect to their grain yield and other traits. Sharma et al. (2010) explained that wheat GY is highly influenced by production environments. More importantly, the significant genotypic effect obtained on GY and other traits reveals the existence of sufficient genetic variability among the wheat germplasms that can be exploited in the heat tolerance breeding programs (Degewione et al., 2013).

The performance of the wheat genotypes was much higher in the normal season than in the late season, which agrees with numerous reports of many researchers on impact of heat stress on wheat. Rahman et al. (2009) further stated that in response to higher temperature, there was significant reduction in the number of days to booting, heading, flowering, and maturity. Singh et al. (2007) observed that heat stress had negative impact on the $\mathrm{PH}$ of wheat as reported in the present study. Exposure to higher temperatures can significantly reduce GY (Tewolde et al., 2006). The higher temperature associated with the late season as evidently reported in the meteorological data impacted heat stress on the crop leading to the greater significant reduction in the all the traits especially the GY. Nonetheless, the 30 top genotypes in each of the environments yielded above $1 \mathrm{t} \mathrm{ha}^{-1}$. The GY obtained agrees with the economic yield threshold reported by Hunt and Kirkegaard (2011) that yield of less than $1 \mathrm{t} \mathrm{ha}^{-1}$ of wheat is generally regarded as noncommercial, but in certain parts of the world like South Australia, a GY lower than $1 \mathrm{t} \mathrm{ha}^{-1}$ is still considered useful. Reliably, genotype 148 that was consistently among the 30 top genotypes in all the environments, as well as genotypes 172 and 124 that were consistent in three environments are recommended for both heat favorable and heat stressed environments. Al-Otayk (2010) argued that a genotype with stable and high yield across different environments would be a more suitable cultivar and perhaps a donor parent for further breeding for heat tolerance. Specifically, genotypes $22,30,60,69$, and 58 that were consistently among the top yielding genotypes in the two late seasons will be ideal for heat stressed environments only, while genotypes $38,49,51$, and 162 that were consistent in the two normal seasons are recommended for heat favorable conditions only.

The first relative heat tolerance graph (Figure 1) reveals that the grain loss (\%) due to high temperature experienced in the late season 1 in relation to the normal season 1 was in the range of $33.69 \%$ to $77.95 \%$, whereas the second RHT graph (Figure 2) displays that the grain yield loss was in the 
range of $65.28 \%$ to $95.83 \%$. Rehman et al. (2009) previously reported that wheat planted in the late season suffered drastic yield loss which exceeded 50\%. Consistently, genotypes 119 and 30 that were among the 15 heat tolerant genotypes in the two RHT figures show that these genotypes could be genetic sources for heat tolerance breeding program especially genotype 30 that was among the 30 top yielding genotypes in the two late seasons. Apart from genotype 30, genotype 148 that was among the 30 top high yielding genotypes in all the environments and among the 15 heat tolerant genotypes in one RHT figure could be genetically rich in high GY and heat tolerance potentials. The range of the RHT was higher in the second graph (late season 2 vs. normal season 2) than in the first RHT graph (late season 1 vs. normal season 1). The higher maximum and minimum temperatures recorded in the late season 2 than in the late season 1, as evident in the meteorological Tables 3 and 4, could have led to lower GY in the late season 2 .

The correlation showed that early maturing genotypes are ideal for heat stressed environments, but late maturing genotypes will be suitable for heat favorable environments. Grain yield significantly correlated negatively with $\mathrm{DH}$, DM, and GFD in late season 2 indicating the faster the crop matures, the lesser the crop is exposed to the extended heat stress, hence more GY will be achieved. Conversely, DH, DM, and GFD correlated positively with GY in the normal seasons suggesting the longer the maturation of the crop especially if the grain filling duration is prolonged, the more the increase in the GY. Thus, late maturing genotypes will be very suitable in heat favorable conditions. Unpredictably, the GY correlated positively with DM (though not significant) in late season 1. This could suggest that the wheat germplasm did not experienced very high temperature as in the late season 2, which was markedly obvious in the meteorological data. This underscores that even though early maturing genotypes are ideally suitable for heat stressed conditions; late maturing genotypes may still be suitable for areas or late seasons that experience tolerably high temperature. In this case, the crop may still be economically able to produce high GY regardless of the endurable heat stress.

This suggests that days to maturity could be favorably selected for enhanced grain yield, except under intense and protracted heat stress especially during the late growing season. Under intense heat stress, fast maturing genotypes will be ideal by employing escape mechanisms to avoid the prolonged terminal heat stress that normally occurs particularly in the tropics and sub-tropics. Menshawy (2007) also indicated that early maturing cultivars are preferable to escape heat stress injury that occurs at the end of the growing season. These early maturing genotypes possess earliness per se genes that hasten the developmental and flowering time under heat stressed environments as soon as vernalization and photoperiod requirements have been fulfilled. As obtained in this present study, Amiri et al. (2013) observed consistent positive correlation between GY and PH in both favorable and drought environments in 80 bread wheat drought tolerance study. In addition, the significant positive correlation obtained between GY and PH in both the normal and late seasons showed that the trait could be favorably selected for increased GY under both heat favorable and heat stressed conditions. However, Tadesse et al. (2010) emphasized that attention needs to be given in improving lodging resistance otherwise; selection for taller plants will result in lodging during high rainfall seasons, which reduces yield and increases disease development.

Khan and Naqvi (2011) earlier reported high heritability estimates for DH, DM, GFD, and $\mathrm{PH}$, which are close to results of the present study. The heritability estimates for different characters depend upon the genetic makeup of the breeding materials studied; therefore knowledge about these values in the materials in which breeders are interested is of great significance (Kahrizi et al., 2010). High heritability estimates indicate that the selection for these characters will be effective, being less influenced by environmental effects (Maniee et al., 2009). Heritability, a measure of the phenotypic variance attributable to genetic causes, has predictive function in breeding crops (Songsri et al., 2008). It also provides an estimate of the genetic advance a breeder can expect from selection applied to a population under certain environment (Khan and Naqvi, 2011). The higher the heritability estimates, the simpler are the selection procedures (Khan et al., 2008). In general, it is considered that if a character is governed by non-additive gene action, it may give high heritability but low genetic advance, whereas if the character is governed by additive gene action, both heritability and genetic advance would be high (Eid, 2009). The heritability value alone provides no indication of the genetic progress that would result in selecting the best individual, but heritability estimates along with the genetic advance is considered more useful (Ajmal et al., 2009).

Thus, high broad heritability and genetic advance estimates observed in DH and DM indicate that these traits have high response to selection and will be very useful in indirect heat tolerance breeding program. The high values of genetic advance and heritability indicates that these traits are under additive gene effects, and therefore selection in early generations for these traits will be effective. Plant height that recorded the highest genetic advance and high to moderate heritability estimates will also be vital in heat tolerance breeding program. However, Kahrizi et al. (2010) observed low heritability of 0.1285 and genetic advance value of 0.03 in GY in durum wheat as reported in the present study. The low heritability and genetic advance estimates obtained in GY suggest nonadditive gene effects, thus the scope for improvement via this trait may be limited. Previously, GY has been the major direct breeding criterion for improvement in wheat, and it appears that further improvement through direct selection of the GY may be difficult owing to the low heritability and genetic advance estimates observed in the trait in the present study. Thus, indirect breeding for increased GY under high temperature using morpho-physiological traits may be easier and more feasible. 


\section{CONCLUSIONS}

The significant impact of the heat stress on performance of the wheat germplasm especially on the grain yield underlines the urgent need for breeding for heat tolerance. However, the significant genotypic effect obtained indicates the existence of sufficient genetic variability among the wheat germplasm that can be exploited in the heat tolerance breeding programs. Reliably, genotypes 148, 172, and 124 are recommended for both heat favorable and heat stressed environments due to their high grain yield stability in all the environments. Genotypes 119 and 30 that were among the 15 heat tolerant genotypes in the relative heat tolerance figures show that these genotypes could be genetic sources for heat tolerance breeding program. Apart from genotype 30 that was among the top yielding genotypes in the two late seasons, genotype 148 could possess both high grain yield and heat tolerance attributes for heat stressed environments.

The correlation showed that early maturing genotypes are ideal for heat stressed environments, but late maturing genotypes will be suitable for heat favorable environments. In addition, the correlation further reveals that plant height could be positively selected for increased grain yield under both heat favorable and heat stressed conditions, however, attention needs to be given in improving lodging resistance also to avoid lodging during high rainfall and wind associated areas. High to moderate heritability and genetic advance values observed in all the traits except in grain yield indicate that these traits could be under additive gene effects, and therefore selection in early generations for these traits will be effective in indirect heat tolerance breeding programs. The low heritability and genetic advance estimates obtained in grain yield suggest nonadditive gene effects, thus direct improvement of grain yield under high temperature may be limited. Therefore, indirect improvement of grain yield using other traits with high heritability and genetic advance estimates as obtained in this study will be much more feasible and rewarding.

\section{ACKNOWLEDGEMENTS}

We thank Grains Research and Development Corporation (GRDC), Australia and the International Centre for Agricultural Research in the Dry Areas (ICARDA), Syria for funding this research.

\section{REFERENCES}

Ajmal, S.U., N. Zakir, and M.Y. Mujahid. 2009. Estimation of genetic parameters and characters association in wheat. Journal of Agricultural and Biological Science 1:15-18.

Al-Otayk, S.M. 2010. Performance of yield and stability of wheat genotypes under high stress environments of the central region of Saudi Arabia. JKAU: Meteorology, Environment and Arid Land Agriculture 21:81-92. doi:10.4197/met. 21-1.6.1-12.
Amiri, R., S. Bahraminejad, and S. Jalali-Honarmand. 2013. Effect of terminal drought stress on grain yield and some morphological traits in 80 bread wheat genotypes. International Journal of Agriculture and Crop Sciences 5:1145-1153.

Degewione, A., T. Dejene, and M. Sharif. 2013. Genetic variability and traits association in bread wheat (Triticum aestivum L.) genotypes. International Research Journal of Agricultural Sciences 1(2):19-29.

Eid, M.H. 2009. Estimation of heritability and genetic advance of yield traits in wheat (Triticum aestivum L.) under drought condition. International Journal of Genetics and Molecular Biology 1(7):115-120.

Fehr, W.R. 1993. Principles of cultivar development. Vol. 1. Theory and technique. Macmillan Publishing Company, New York, USA.

Gill, B., R. Appels, A. Botha-Oberholster, C. Buell, J. Bennetzen, B. Chalhoub, et al. 2004. A workshop report on wheat genome sequencing: international genome research on wheat consortium. Genetics 168:1087-1096.

Gupta, P.K., R.R. Mir, A. Mohan, and J. Kumar. 2008. Wheat genomics: Present status and future prospects. International Journal of Plant Genomics doi:10.1155/2008/896451.

Haque, M.Z., M.M. Hasan, M.M.R. Rajib, and M.M. Hasan. 2009. Identification of cultivable heat tolerant wheat genotypes suitable for Patuakhali district in Bangladesh. Journal of the Bangladesh Agricultural University 7(2):241-246.

Hunt, J.R., and J.A. Kirkegaard. 2011. Re-evaluating the contribution of summer fallow rain to wheat yield in southern Australia. Crop Pasture Science 62:915-929.

Johnson, H.W., H.F. Robinson, and R.E. Comstock. 1955. Estimates of genetic and environmental variability in soybeans. Agronomy Journal 47(7):314-318.

Kahrizi, D., K. Cheghamirza, M. Kakaei, R. Mohammadi, and A. Ebadi. A. 2010. Heritability and genetic gain of some morphophysiological variables of durum wheat (Triticum turgidum var. durum). African Journal of Biotechnology 9:4687-4691.

Khan, N., and F.N. Naqvi. 2011. Heritability of morphological traits in bread wheat advanced lines under irrigated and non-irrigated conditions. Asian Journal of Agricultural Sciences 3:215-222.

Khan, H., H. Rahman, H. Ahmed, and H. Ali. 2008. Magnitude of heterosis and heritability in sunflower over environments. Pakistan Journal of Botany 1:301-308.

Maniee, M., D. Kahrizi, and R. Mohammadi. 2009. Genetic variability of some morpho-physiological traits in durum wheat (Triticum durum Desf.) Journal of Applied Sciences 9:1383-1387.

Menshawy, A.M.M. 2007. Evaluation of some early bread wheat genotypes under different sowing dates. 1. Earliness characters. Egyptian Journal of Plant Breeding 11:25-40.

Mohamed, N.E.M. 2013. Genotype by environment interactions for grain yield in bread wheat (Triticum aestivum L.) Journal of Plant Breeding and Crop Science 5(7):150-157. doi:10.5897/ JPBCS2013.0390.

Motamedi, M., H.R. Naserierad, R. Naseri, and A. Soleymanifard. 2012. Assessment of genotype $\times$ environment interaction for grain yield in bread wheat genotypes. International Journal of Agriculture and Crop Sciences 4:1366-1370.

Paliwal, R., M.S. Roder, U. Kumar, J.P. Srivastava, and A.K. Joshi. 2012. QTL mapping of terminal heat tolerance in hexaploid wheat (T. aestivum L.) Theoretical and Applied Genetics 125:561-575.

Rahman, M.A., J. Chikushi, S. Yoshida, and J.M.S. Karim. 2009. Growth and yield components of wheat genotypes exposed to high temperature stress under controlled environment. Bangladesh Journal of Agricultural Research 34:361-372. 
Rajaram, S., and H. Braun. 2008. Wheat yield potential. p. 103107. In Reynolds, M.P., J. Pietragalla, and H.J. Braun (eds.) International Symposium on Wheat Yield Potential: Challenges to International Wheat Breeding. CIMMYT, Mexico, D.F.

Rehman, A., I. Habib, N. Ahmad, M. Hussain, M. Arif Khan, J. Farooq, et al. 2009. Screening wheat germplasm for heat tolerance at terminal growth stage. Plant Omics Journal 2(1):9-19.

Ryan, J., S. Masri, S. Garabet, J. Diekmann, and H. Habib. 1997. Soil of ICARDA's agricultural experiment stations and sites: Climate, classification, physical, and chemical properties and land use. International Center for Agricultural Research in the Dry Areas (ICARDA), Aleppo, Syria.

Semenov, M.A. 2009. Impacts of climate change on wheat in England and Wales. Journal of the Royal Society Interface 6:343-350

Sharma, R.C., A.I. Morgounov, H.J. Braun, B. Akin, M. Keser, D. Bedoshvili, et al. 2010. Identifying high yielding stable winter wheat genotypes for irrigated environments in Central and West Asia. Euphytica 171:53-64. doi.org/10.1007/ s10681-009-9992-6.

Sikder, S., and N.K. Paul. 2010. Evaluation of heat tolerance of wheat cultivars through physiological approaches. Thai Journal of Agricultural Science 43(4):251-258

Singh, J.P., P. Shambhoo, K.N. Singh, and S. Randhir. 2007. Screening of heat tolerant wheat varieties by membrane thermostability index in relation to yield and yield attributing traits. International Journal of Plant Sciences. Muzzaffarmagar 2(2):159-165
Songsri, P., S. Joglloy, T. Kesmala, N. Vorasoot, C.P.A. Akkasaeng, and C. Holbrook. 2008. Heritability of drought resistance traits and correlation of drought resistance and agronomic traits in peanut. Crop Science 48:2245-2253.

Tadesse, W., O. Abdalla, F. Ogbonnaya, K. Nazari, I. Tahir, and M. Baum. 2012. Agronomic performance of elite stem rust resistant spring wheat genotypes and association among trial sites in the Central and West Asia and North Africa Region. Crop Science 52:1105-1114. doi:10.2135/cropsci2011.09.0463.

Tadesse, W., Y. Manes, R.P. Singh, T. Payne, and H.J. Braun. 2010. Adaptation and performance of CIMMYT spring wheat genotypes targeted to high rainfall areas of the world. Crop Science 50:240-248. doi:10.2135/cropsci2010.02.0102.

Tewolde, H., C.J. Fernandez, and C.A. Erickson. 2006. Wheat cultivars adapted to post-heading high temperature stress. Journal of Agronomy and Crop Science 192:111-120.

Wahid, A., S. Gelani, M. Ashraf, and M.R. Foolad. 2007. Heat tolerance in plants: an overview. Environmental and Experimental Botany 61(3):199-223.

Zadoks, J.C., T.T. Chang, and C.F. Konzak. 1974. A decimal code for the growth stage of cereals. Weed Research 14:415-421. 